\title{
Genotyping of Brazilian Giardia duodenalis human axenic isolates
}

\author{
Coradi ST (1), David EB (2), Oliveira-Sequeira TCG (2), Ribolla PEM (2), Carvalho TB (2), Guimarães S (2)
}

(1) Department of Biological Sciences, Sacred Heart University (USC), Bauru, São Paulo State, Brazil; (2) Department of Parasitology, Botucatu Biosciences Institute, São Paulo State University (UNESP - Univ Estadual Paulista), Botucatu, São Paulo State, Brazil.

\begin{abstract}
Giardia duodenalis is a complex species that comprises at least seven distinct genetic groups (A to $G$ ), but only genotypes $A$ and $B$ are known to infect humans and a wide variety of other mammals. Regardless of biological, biochemical and antigenic analysis, several isolates maintained in vitro were not genetically typed yet. So, in the present study, five Brazilian axenic isolates obtained from asymptomatic and symptomatic patients were typed in order to determine the major genetic groups to which the isolates belonged. DNA was extracted from axenic trophozoites, fragments of glutamate dehydrogenase ( $g d h)$ and triosephosphate isomerase (tpi) genes were amplified by PCR and the isolate genotyping was carried out using restriction fragment length polymorphism (RFLP) and DNA sequencing for both genes. The results revealed that all isolates were assigned to genotype $A$ at both analyzed loci. Indeed, DNA sequence analysis classified the four isolates obtained from asymptomatic individuals into subtype All, while the isolate obtained from the symptomatic patient was typed as subtype Al. Despite of the limited number of isolates assessed, the findings presented herein provide interesting insights on the occurrence of Giardia genotypes in Brazil and hold the perspective for future molecular and epidemiological investigations.
\end{abstract}

Key words: Giardia duodenalis, axenic isolates, molecular typing, genotype.

Giardia duodenalis is a zoonotic protozoan that parasites the small intestine of humans and a range of other mammals. This parasite has a worldwide distribution and it is one of the most common nonviral causes of diarrheal disease in humans, mainly among children in developing countries. In developed countries, G. duodenalis is a frequent cause of epidemic waterborne diarrheal diseases, since numerous outbreaks of giardiasis associated with contaminated water have been reported (1).

During the last 15 years, molecular studies have suggested that $G$. duodenalis is a complex species that includes morphologically indistinguishable isolates that are, however, genetically distinct. Previous genetics analysis of human and animal isolates have shown that $G$. duodenalis comprises at least seven distinct groups, referred to as genotypes A to $G$ (2). Among these groups, only genotypes $\mathrm{A}$ and $\mathrm{B}$ are known to infect humans, as well as a wide variety of other mammals. In addition to the previously described genotypes, other groups have been proposed, such as genotype $\mathrm{H}$ identified in seals, but their existence has not yet been clearly supported (3).

Before the possibility to characterize Giardia isolates obtained directly from human feces, investigations conducted to correlate genetic variability of the isolates to the host-parasite relationship required the in vitro propagation of the protozoan (4). In view of this, in different geographical regions, a number of isolates was established in axenic cultures, most of them derived from humans living in developing 
countries where Giardia infection is endemic. Regardless of biological, biochemical and antigenic analysis, several isolates maintained in vitro were not genetically typed yet.

Lately, in Mexico, some investigators have reported the genetic analysis of independently acquired axenic isolates established from humans (5-7). In Brazil, despite the advent of Giardia axenization, few autochthonous isolates have been established from human stool specimens and, to date, there is only one investigation that evaluated genetic variability among three axenic strains obtained from patients living in Minas Gerais state (8).

Therefore, we proposed herein the genotyping of five Brazilian axenic isolates obtained from cysts of patients from São Paulo state, for which just proteolytic activity and susceptibility to potential antigiardial agents are available yet (9-12). For this purpose, we employed PCR amplification of two commonly used genetic markers, the $g d h$ and tpi genes.

Axenic trophozoites of strains isolated at the Giardiasis Laboratory (UNESP) in Botucatu, São Paulo, were grown in filter-sterilized TYI-S-33 medium supplemented with bovine bile in $5 \mathrm{~mL}$ Vacutainer ${ }^{\oplus}(\mathrm{BD}, \mathrm{USA})$ tubes at $37^{\circ} \mathrm{C}(13)$. All the isolates were recovered from cysts in the patient's feces, but four of them were isolated from asymptomatic carriers (BTU-1, BTU-2, BTU-6, and BTU-10) and one (BTU-11) was established from a symptomatic individual presenting diarrhea, flatulence and abdominal cramps (Table 1).

For molecular characterization, total DNA from axenic trophozoites was extracted using the GFX $^{\circledR}$ Genomic Blood DNA Purification kit (GE Healthcare, UK) procedure, according to the manufacturer's instructions. Molecular characterization of $G$. duodenalis isolates was performed using two loci, glutamate dehydrogenase $(g d h)$ and triose phosphate isomerase (tpi) genes. The genomic DNA was submitted to a semi-nested procedure to amplify a 432-bp region from the $g d h$ gene and also to a nested PCR reaction for 530-bp fragment amplification of the tpi gene $(14,15)$. Reactions were performed on a Mastercycler ${ }^{\circledast}$ gradient (Eppendorf,Germany) and the resulting PCR products were visualized on ethidium bromide stained $1.5 \%$ agarose gels.

Giardia genotyping was carried out using restriction fragment length polymorphism (RFLP) and DNA sequencing for both $g d h$ and tpi genes. For PCR-RFLP assays, the $g d h$ and tpi amplification products were digested, respectivelly, with two units of the endonucleases NalaIV and Ddel (New England Biolabs Inc., USA), in a final volume of $20 \mu \mathrm{L}$ for three hours at $37^{\circ} \mathrm{C}(14,15)$. Restriction fragments were visualized on ethidium bromide stained $2 \%$ agarose gels.

For sequencing, after electrophoresis of the semi-nested PCR $(g d h)$ and nested PCR (tpi) products, bands were excised from agarose gels, purified using the Ultrafree ${ }^{\circledast}$ DA kit (Millipore Corp., USA) and sequenced on both strands by using online sequencing service at Macrogen Inc. (Koreia). The nucleotide sequences obtained were manually corrected and multiple alignments for each locus were performed by using Clustal X program (16). Sequence searches obtained were conducted using BLAST of the National Center for Biotechnology Information (http://www.ncbi. nlm.nih.gov/BLAST) and the analysis included reference sequences of the homologous genes from representative isolates of genotypes $\mathrm{A}$ and B deposited in Genbank under the following accession numbers: L40509, L40510, L40508, AFO69059 and U57897. The phylogenetic and molecular analyses were performed by using the program MEGA (http://www.mega-software.net).

For both $g d h$ and tpi genes, PCR products of the expected size were generated from all five autochthonous strains. The $g d h$ PCR-RFLP assay showed a fragment pattern identical to genotype $A$ in all isolates (Table 1). Indeed, NalIV digestion allowed the discrimination between subtypes AI (restriction bands of 90, 120 and $150 \mathrm{bp}$ ) and AII (restriction bands of 70, 80, 90 and 120 bp). Thus, four isolates (BTU-1, BTU-2, BTU-6 and BTU-10) corresponded to the AII subtype and only one (BTU-11) to the AI. The tpi PCRRFLP analysis using the enzyme Ddel revealed a restriction fragment pattern (bands of 204 and $326 \mathrm{bp)}$ compatible with genotype A for all the axenic isolates. The enzyme Ddel was not capable of distinguishing subtypes.

Both $g d h$ and tpi sequence analysis revealed the same genotypes as the PCR-RFLP assays (Table 1 and Figure 1). Among the axenic isolates, four of them (BTU-1, BTU-2, BTU-6 and BTU-10) were confirmed as genotype AII and one (BTU-11) as genotype AI. All the axenic isolate sequences 
Table 1. Characteristics of Brazilian axenic isolates of Giardia duodenalis and summary of genotyping results

\begin{tabular}{c|c|c|c|c}
\hline Code & Age (years)/sex & Clinical status & Origin & Genotypes* \\
\hline BTU-1/89 & $7 / F$ & Asymptomatic & Botucatu, SP & All \\
\hline BTU-2/89 & $12 / \mathrm{M}$ & Asymptomatic & Botucatu, SP & All \\
\hline BTU-6/89 & $7 / \mathrm{M}$ & Asymptomatic & Botucatu, SP & All \\
\hline BTU-10/90 & $21 / \mathrm{M}$ & Asymptomatic & Botucatu, SP & All \\
\hline BTU-11/91 & $* * / M$ & Symptomatic & São Paulo, SP & \multicolumn{2}{|c}{ Al } \\
\hline
\end{tabular}

M: male, F: female; *genotyping by $g d h$ and tpi genes; **information not available.

from both genes showed 100\% homology with GenBank reference sequences, so none of them revealed any single nucleotide polymorphism (SNP).

The phylogenetic analysis of $g d h$ gene showed that axenic isolates of Giardia duodenalis were clearly grouped in genotypes AI or AII (FIgure 1). Thus, the $g d h$ gene allowed a more consistent subgrouping (AI and AII) of isolates than tpi gene, which in general best subdivide genotype B.

In spite of the interest on unraveling the complex questions about epidemiology of giardiasis in endemic areas; in Brazil, few studies have focused on genotyping autochthonous isolates obtained from infected humans and animals. Although a limited number of isolates was analyzed in this study, the present results outline some pertinent aspects about the occurrence of Giardia genotypes in our country. Thus, DNA sequence analysis and PCR-RFLP assay both in tpi and $g d h$ genes, revealed the genotype $\mathrm{A}$ in all axenic strains isolated in São Paulo state. Our results corroborate recent investigations in which human axenic isolates and isolates obtained directly from human fecal samples were characterized as genotype A $(8,17-19)$.

To date, such studies are scarce in Brazil; however, observations have indicated that the distribution of genotypes may vary in populations living in different regions. The first study was
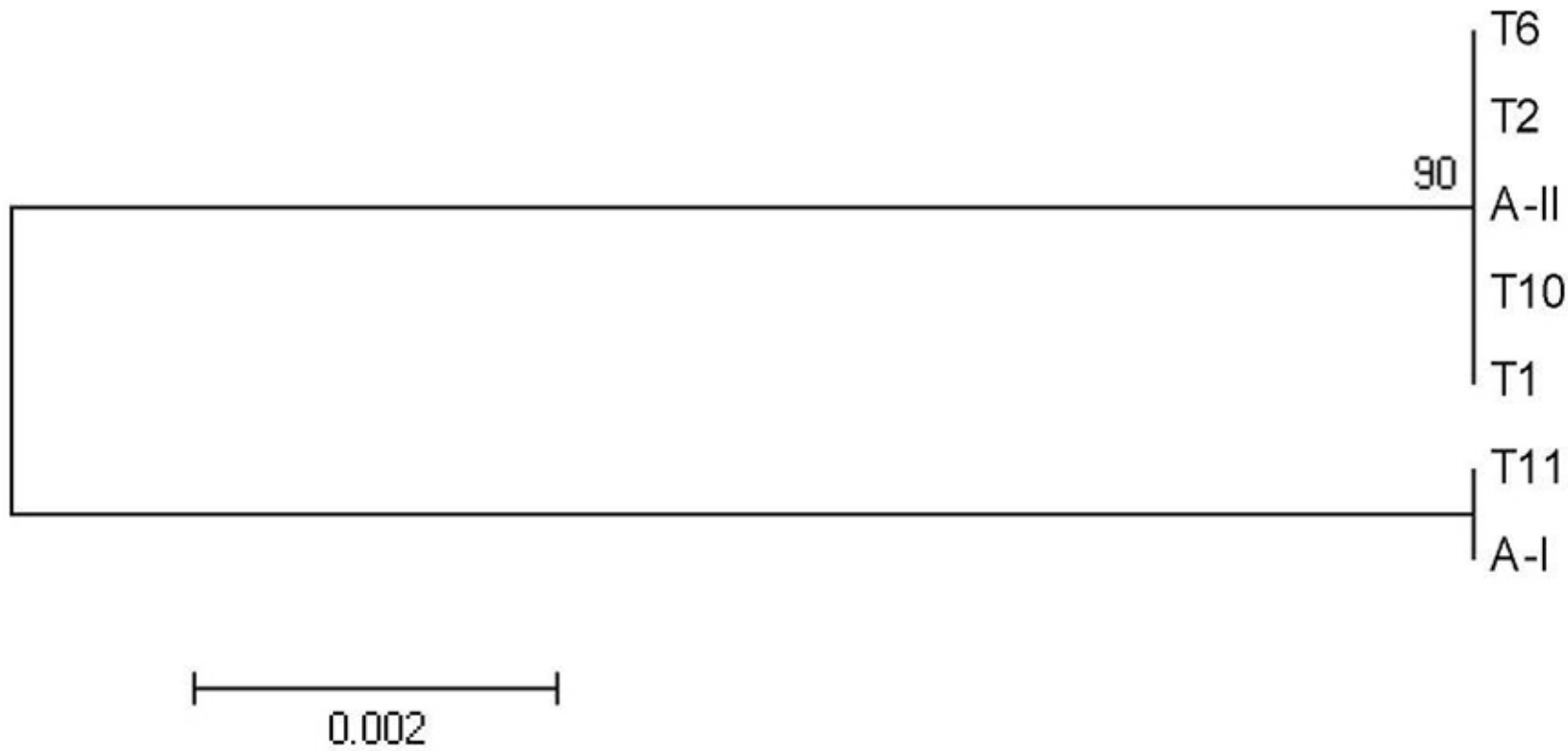

Figure 1. Neighbor-joining phylogenetic analysis of Giardia duodenalis axenic isolates at gdh locus. Al (L40509) and All (L40510) correspond to sequences obtained in GenBank and T1, T2, T6, T10 and T11 correspond to the axenic isolates BTU-1, BTU-2, BTU-6, BTU-10 and BTU-11, respectively. 
published by Volotão et al. (17) in 2007, which empolyed PCR and gene sequencing of $\beta$-giardin to demonstrate the occurrence of only genotype $\mathrm{A}$ in isolates from children attended in a daycare center at the municipality of Rio de Janeiro. In the same year, Souza et al. (18), analyzing the sequence of the $g d h$ gene, identified genotypes $\mathrm{A}$ and $\mathrm{B}$ in isolates from patients hospitalized in four cities of São Paulo state and pointed out the predominance of genotype A. In contrast, Kohli et al. (19) identified genotypes A and B in isolates from children living in a deprived community in the northeastern Brazil and reported the predominance of genotype $B$ in this population. In this context and considering our results, it is worth highlighting that all the axenic isolates were obtained from individuals living in cities from the same geographical area of the country, i.e., the Southeast region.

Besides distinguishing the major genotypes of Giardia, the isolates were typed at the subgroup level and among the axenic isolates assessed, four of them (BTU-1, BTU-2, BTU-6 and BTU10) were classified as AII subtype and only one (BTU-11) as AI subtype. Considering the gene locus used for assemblage differentiation, $g d h$ showed greater variability among genotype A, avoiding a better discrimination of the subtypes AI and AII. According to a previous report, the tpi gene is known to be highly polymorphic among genotype B isolates (20).

The occurrence of subgenotype AII is consistent with recent results of Souza et al. (18), who found that most isolates from human patients living in São Paulo state belonged to subgroup AII. Interestingly, preliminary results of an investigation still in progress have shown that AII is the most prevalent genotype detected among children living in a neighboring community of Botucatu city (unpublished data). Additionally, in the current study, the axenic isolate identified as genotype AI was isolated in Botucatu from a patient living in the urban area of São Paulo city that had a history of travel to different regions of the country. Furthermore, the four other isolates were obtained from individuals living in the municipality of Botucatu. This finding suggests epidemiological and molecular evidence of genetic similarities among G. duodenalis isolates of individuals living in the same region. Even so, in this context, Ponce-Macotela et al. (5) reinforce the importance of care when interpreting such data, because the lack of one genotype assemblage and the abundance of another one may reflect a local or regional epidemic involving the genotype.

Another point that corroborates previous studies is that among the axenic isolates none was identified as genotype B. According to some authors, this absence is not unusual, due to the selection of genotype A during establishment of axenic cultures, which may favor the genotype $\mathrm{A}$ to the detriment of genotype $B(5,6)$.

Besides the matter on the distribution of genotypes, another controversial issue related to Giardia genotypes is the clinical variability of the infection among individuals infected with assemblages A and B. Some researchers have pointed out that symptoms are more associated with genotype $\mathrm{A}$, while others have found that genotype $\mathrm{B}$ infections are more likely to be symptomatic (21-24). Without any pretension to correlate genotype and clinical presentation, our observations are outside the expected pattern, since isolates from asymptomatic and symptomatic individuals were classified into the same genotype, however, as different subtypes. So, in contrast with isolates recovered from asymptomatic individuals that were classified as AII, the infection of the symptomatic case that presented diarrhea, flatulence and abdominal cramps was caused by the subtype AI. This situation should reinforce the fact that, until today, results that have been reported may be inconsistent or have led some authors to believe that there is no relationship between genotypes and the development and severity of the infection (6).

Once again, we know that the reduced number of analyzed isolates may interfere with the interpretation of results. However, since only a few studies on Giardia typing have been conducted in Brazil, the observations assembled here provide insights on subgenotypes that may exist within a population and also offer perspectives for future genotyping of isolates obtained directly from feces of hosts with the aim of elucidating in more detail the biological and epidemiological significance of Giardia genotypes in endemic areas.

\section{COPYRIGHT}

(C) CEVAP 2011

\section{SUBMISSION STATUS}

Received: March 17, 2011.

Accepted: June 7, 2011. 
Abstract published online: June 17, 2011.

Full paper published online: August 31, 2011.

\section{CONFLICTS OF INTEREST}

There is no conflict.

\section{FINANCIAL SOURCE}

The State of São Paulo Research Foundation (FAPESP) provided the financial grants (process number 06/56151-3).

\section{CORRESPONDENCE TO}

SEMÍRAMIS GUIMARÃES, Departamento de Parasitologia, Instituto de Biociências, UNESP, Botucatu, SP, 18618-000, Brasil. Phone: +55 14 3811 6239. Email: sgviana@ibb.unesp.br.

\section{REFERENCES}

1. Adam RD. Biology of Giardia lamblia. Clin Microbiol Rev. 2001;14(3):447-5.

2. Monis P, Andrews RH, Mayrhofer G, Ey PL. Genetic diversity within the morphological species Giardia intestinalis and its relationship to host origin. Infect Genet Evol. 2003;3(1):29-38.

3. Feng Y, Xiao L. Zoonotic potential and molecular epidemiology of Giardia species and giardiasis. Clin Microbiol Rev. 2011;24(1):110-40.

4. Thompson RC, Limbery AJ. Genetic variability in parasites and host-parasite interactions. Parasitol. 1996;112:S7-22

5. Ponce-Macotela $\mathrm{M}$, Martínez-Gordillo $\mathrm{MN}$, Bermúdez-Cruz RM, Salazar-Schettino PM, OrtegaPierres G, Ey PL. Unusual prevalence of the Giardia intestinalis A-II subtype amongst isolates from humans and domestic animals in Mexico. Int J Parasitol. 2002; 32(9):1201-2.

6. Cedillo-Rivera R, Darby JM, Enciso-Moreno JA, Ortega-Pierres G, Ey PL. Genetic homogeneity of axenic isolates of Giardia intestinalis derived from acute and chronically infected individuals in Mexico. Parasitol Res. 2003; 90(2):119-23.

7. Eligio-García L, Corte-Campos A, Jiménez-Cardoso E. Genotype of Giardia intestinalis isolates from children and dogs and its relationship to host origin. Parasitol Res. 2005;97(1):1-6.

8. Rocha MO, Gomes MA, Costa AO, Furst C, Silva EF. Molecular characterization of Brazilian human Giardia duodenalis isolates using isoenzyme and random amplified polymorphic DNA analysis. Diagn Microbiol Infect Dis. 2003;46(4):273-8.

9. Guimarães S, Sogayar MI, Franco MF. Protease activity in Giardia duodenalis trophozoites of axenic strains isolated from symptomatic and asymptomatic patients. Mem Inst Oswaldo Cruz. 2003; 98(1):77-81.

10. Coradi ST, Guimarães S. Giardia duodenalis: protein substrates degradation by trophozoite proteases. Parasitol Res. 2006; 99(2):131-6.
11. de Carvalho TB, David EB, Coradi ST, Guimarães S. Protease activity in extracellular products secreted in vitro by trophozoites of Giardia duodenalis. Parasitol Res. 2008;104(1):185-90.

12. Freitas SF, Shinohara L, Sforcin JM, Guimarães S. In vitro effects of propolis on Giardia duodenalis trophozoites. Phytomedicine. 2006;13(3):170-5.

13. Keister DB. Axenic culture of Giardia lamblia in TYI-S-33 medium supplemented with bile. Trans R Soc Trop Med Hyg. 1983;77(4):487-8.

14. Read CM, Monis PT, Thompson RCA. Discrimination of all genotypes of Giardia duodenalis at the glutamate dehydrogenase locus using PCR-RFLP. Infect Genet Evol. 2004; 4(2):125-30.

15. Sulaiman IM, Fayer R, Bern C, Gilman RH, Trout JM, Schantz PM, et al. Triosephosphate isomerase gene characterization and potential zoonotic transmission of Giardia duodenalis. Emerg Infect Dis. 2003;9(11):1444-52.

16. Thompson JD, Gibson TJ, Plewniak F, Jeanmougin F, Higgins DG 1997. The ClustalX windows interface: flexible strategies for multiple sequence alignment aided by quality analysis tools. Nucleic Acids Res. 1997;24(25):4876-82.

17. Volotão AC, Costa-Macedo LM, Haddad FS, Brandão A, Peralta JM, Fernandes O. Genotyping of Giardia duodenalis from human and animal samples from Brazil using beta-giardin gene: a phylogenetic analysis. Acta Trop. 2007;102(1):10-9.

18. Souza SL, Gennari SM, Richtzenhain LJ, Pena HF, Funada MR, Cortez A, et al. Molecular identification of Giardia duodenalis isolates from humans, dogs, cats and cattle from the state of São Paulo, Brazil, by sequence analysis of fragments of glutamate dehydrogenase $(g d h)$ coding gene. Vet Parasitol. 2007;149(3-4):258-64.

19. Kohli A, Bushen OY, Pinkerton RC, Houpt E, Newman $\mathrm{RD}$, Sears CL, et al. Giardia duodenalis assemblage, clinical presentation and markers of intestinal inflammation in Brazilian children. Trans R Soc Trop Med Hyg. 2008; 102(7):718-25.

20. Lalle M, Bruschi F, Castagna B, Campa M, Pozio E, Cacció SM. High genetic polymorphism among Giardia duodenalis isolates from Sahrawi children. Trans R Soc Trop Med Hyg. 2009; 103(8):834-8.

21. Read C, Walters J, Robertson ID, Thompson RC. Correlation between genotypes of Giardia duodenalis and diarrhoea. Int J Parasitol. 2002;32(2):229-31.

22. Haque R, Roy S, Kabir M, Stroup SE, Mondal D, Houpt ER. Giardia assemblage A infection and diarrhea in Bangladesh. J Infec Dis. 2005;192(12):2171-3.

23. Homan WL, Mank TG. Human giardiasis: genotype linked differences in clinical symptomatology. Int J Parasitol. 2001;31(8):822-6.

24. Gelanew T, Lalle M, Hailu A, Pozio E, Cacció SM. Molecular characterization of human isolates of Giardia duodenalis from Ethiopia. Acta Trop. 2007;102(2):92-9. 